\title{
Santos, Boaventura de Sousa (2015). La universidad en el siglo XXI. México: Siglo XXI, 173 páginas.
}

Gabriela Fuentes Reyes y Juan Bernal Aguirre

Universidad Autónoma del Estado México, México

gafure@hotmail.com, juan.beragui@hotmail.com

En su obra "La universidad en el siglo XXI", Souza Santos expone con claridad el complejo problemático al que tiene que hacer frente la centenaria institución educativa de nivel superior y que va desde los problemas producto de su natural resistencia al cambio ante lo vertiginoso que la vida post industrial-capitalista ha ido acompasando y llega hasta conflictos de legitimidad frente a la sociedad y la falta -o recorte- de presupuesto y recursos económicos. Situaciones estas que pueden considerarse -según se colige de lo expuesto por el autor- como la manifestación de una extensa gama de síntomas que han tratado de solventarse gracias a una gestión de tensiones conveniente sólo en la medida "en que busca manejar su posición amenazada a través de una contabilidad de pérdidas y ganancias del desempeño funcional", donde la principal estrategia es eminentemente defensiva y poco proactiva, en palabras del mismo Souza "la universidad ha sido reactiva, dependiente e inmediatista".

Todo esto va encontrando camino conforme se sigue el discurso del autor lusitano, en tanto que su exposición mantiene coherencia, a la vez que realiza, por un lado, una férrea defensa del ente universitario y por otro no deja de criticar objetivamente los errores cometidos, agravados y no resueltos que continúan en operación. A ese respecto se escribe que la génesis de algunos obstáculos se ubica en la forma en que se fue educando en diversos niveles junto con el enfoque que se dio a los tiempos no presentes, y se afirma con la contundente frase "el pasado fue siempre concebido como reaccionario y el futuro como progresista". Esta afirmación es consistente con su visión puesto que en ella se integran el cambio y la promesa de éste, donde la transición es de lo malo y lo indeseado a lo bueno y, por el contrario, lo deseado, dejando claro que dicha promesa de cambio suponía en sí misma la trivialización de lo pasado y la idealización de lo futuro. Con ello, Boaventura realiza una crítica de la ideología burguesa que, según él mismo afirma, ha impuesto su victoria sobre las demás clases a través de la repetición del estado de cosas; y para ello se requería del olvido y superación del pasado con todo y sus sufrimientos, injusticias y opresiones.

La imposición de esa ideología, además, necesitaba de un aparato de reproducción y enseñanza de la misma, superponiendo el actuar protagónico de la clase dominante. La premisa que sirviera como guía se reduce en la abstracción propuesta por Souza, quien dice que "todo conocimiento es una práctica social de conocimiento, es decir, sólo existe en la medida en que es protagonizado y movilizado por un grupo social, actuando en un campo social donde actúan otros grupos rivales protagonistas o titulares de formas rivales de conocimiento."

Así planteado pareciera que las universidades sólo sirvieron, en tiempos contemporáneos, a algunos intereses, sin embargo estas instituciones casi milenarias han tenido que trabajar por sobrevivir y han encontrado un espacio poco cómodo, donde la visión utilitarista empezó a permear y terminó por imponerse casi del todo. Dicha sobrevivencia ha sido puesta en riesgo por otros factores igualmente pujantes e incisivos (tal como es el caso de los enunciados con anterioridad legitimidad y presupuesto-). Dice Souza Santos que "las universidades se enfrentan por todos lados a una situación compleja: la sociedad le hace exigencias cada vez mayores, al mismo tiempo que se hacen cada vez más restringidas las políticas de financiamiento de sus actividades por parte del Estado". Además, estos problemas se van agravando un tanto más si se considera que para poder cumplir con esos dos frentes, primero tienen que saber qué deben hacer y cómo hacerlo, pero ¿sabemos cuáles son los fines que han de perseguir las universidades?, ¿pueden establecerse objetivos igualitarios a todas estas instituciones?

Clín \& Asociados. La historia enseñada. 2016 (22) ISSN 2362-3063 (digital), pp. 123-124 Universidad Nacional del Litaral - Universidad Nacional de La Plata (Santa Fe/La Plata -Argentina) 
Es bien al inicio del segundo capítulo del libro donde el autor comienza a sembrar esta duda al hacer un repaso de los objetivos que tradicionalmente se le habían asignado a la universidad y remarca que aquéllos apenas fueron modificados o aumentados a lo largo de los siglos. Dichos objetivos eran fundamentalmente tres: la enseñanza, la investigación y la difusión de la verdad (la verdad como meta última de los objetivos). Y la naturaleza de aquellos objetivos de carácter casi atemporal y perennes sobre los que se cimentaron las universidades les dieron una idea, falsa para el autor, de que deberían mantener una postura de no-cambio, de continuidad, de sostenimiento de formas y procesos, lo que eventualmente se convertiría en un agente de choque frontal una vez iniciada la década de los sesenta. De esta manera, la universidad se empezó a enfrentar una fuerte contradicción, donde tenía que empezar a decantarse por algún camino: abrirse a la generación del cambio y masificar el conocimiento que con recelo había reservado para sí, o bien continuar con un radical elitismo académico.

Es fácil entender que el cambio es necesario e imperioso, no así las formas en que ha de ser confrontado, cuanto más si para lograrlo requiere enfrentarse a situaciones tan novedosas como decisivas, en contraste con la tradición estática. Tal es el caso de las mismas presiones de mercado a las que todo está sometido todo en este mundo de globalización, comercio y capital, incluyendo, por supuesto, a la universidad. De hecho, esta índole de fuerzas ha tenido tanto impacto en ella que la misma educación superior es ahora producto comerciable. Bajo ese tenor, el autor encuentra cuatro formas en que se ha mercantilizado el bien universitario, partiendo, sobre todo, de lo expuesto en ciertos acuerdos comerciales internacionales. Estas formas son:

-La oferta transfronteriza (sic) sin que haya movimiento físico del consumidor (sic).

-El consumo en el extranjero (sic) a través del movimiento transnacional del consumidor (sic).

-Presencia comercial (sic) establece sucursales en el extranjero con el fin de vender ahí sus servicios (sic).

-Presencia de personal (sic) en la deslocalización temporal en el extranjero de proveedores de servicios en un determinado país, sean ellos profesionales o investigadores.

De esta manera se deja en claro otra tensión surgida -además de la legitimación y recorte presupuestal- y que ahora involucra el destino de lo creado y generado por las universidades, ya que si es la iniciativa privada la que provea los recursos, entonces el conocimiento generado ya no será enfocado a la búsqueda de la verdad, bien por el contrario lo será hacia la inmediata aplicación del mejoramiento de la oferta y producción. Como consecuencia, la humanidad que a sus aulas asista tendrá como carga impositiva la de mejorar y servir a un engranaje comercial demandante de sus energías y cualidades, y que será el beneficiario inmediato; además de ser él el evaluador único del desempeño de universidad y universitarios, también supone la confrontación a la autonomía misma de la universidad y su capacidad de autoevaluación.

Las tensiones brevemente enunciadas son sólo algunas de las profundamente tratadas en la obra en comento y una pequeña parte de la misma, ya que, a pesar de lo oscuro que se mirase el panorama, Souza Santos también conjuntamente expone sus ideas y propuestas para defender a tan noble institución, marcando caminos democráticos y de superación iniciada desde dentro y proyectada con fuerza hacia su exterior, afirmando que "la universidad sólo puede ser una fuerza para el exterior si posee una fuerza interior y la democratización interna de la universidad es la precondición de la constitución de esta fuerza". 